\title{
DEL DÉFICIT AL SUPERÁVIT FISCAL: RAZONES PARA UNA TRANSFORMACIÓN ESTRUCTURAL EN CHILE ${ }^{1}$
}

\author{
José Pablo Arellano
}

Este artículo destaca la solidez fiscal que se ha observado desde 1987 en la economía chilena. Sostiene que el hecho de que sucesivos gobiernos hayan adherido a ella no es casualidad sino que el resultado de reformas legales gestadas desde hace décadas que han concentrado las decisiones en este ámbito en el Presidente, evitando que el resultado fiscal quede librado a una serie de actores independientes y no necesariamente consistentes entre sí. Este marco general se ha reforzado con un presupuesto integral aprobado por el Congreso que, con la excepción de las empresas públicas y de los municipios, abarca a todos los órganos del Estado. En opinión del autor, otros factores que han robustecido la política fiscal son la indexación a la inflación del sistema tributario, el fortalecimiento del Servicio de Impuestos Internos, la prohibición de afectar los impuestos a un determinado gasto.

El logro de cuentas públicas sólidas — un superávit global promedio de 1 por ciento entre 1987 y 2004— tampoco podría haberse alcan-

José Pablo Arellano M. Doctor en economía, Universidad de Harvard. Fue Director Nacional de Presupuesto durante los gobiernos de Patricio Aylwin y Eduardo Frei (1990-1996), y ministro de Educación en el gobierno de Eduardo Frei (19962000). Presidente de Fundación Chile, miembro del directorio de Televisión Nacional y Banco Estado. Actualmente es Presidente Ejecutivo de Codelco.

${ }^{1}$ Este documento es parte del programa de investigaciones de CIEPLAN. Agradezco los comentarios de Mario Marcel, Carlos Salineros y René Cortázar. La responsabilidad es enteramente mía.

Estudios Públicos, 101 (verano 2006). 
zado, en opinión de este estudio, si la decisión de endeudamiento de las entidades del sector público no estuviese centralizada en la Dirección de Presupuestos, si las empresas públicas no requiriesen de autorización expresa del Ministerio de Hacienda para contratar un crédito y si los gobiernos locales no necesitasen de una ley para endeudarse.

La política fiscal, además, se ha perfeccionado a través de la creación de nuevas instituciones que apoyan la necesaria acción contracíclica de esta política. Se destacan y analizan aquí el fondo del cobre y la regla del superávit estructural. Además, contribuyen a una política fiscal prudente la autonomía del Banco Central y el desarrollo de los mercados financieros, verdaderos evaluadores externos de dicha política. Por último, el autor valora el consenso político que se ha generado en torno a una política fiscal responsable.

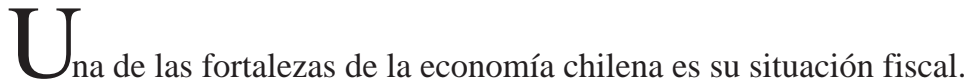
Los indicadores son variados: la deuda pública bajó desde 45\% del PIB en 1990 hasta 13\% en 1998 y después de una leve y transitoria alza durante 2004 ha vuelto al 13\% del PIB ${ }^{2}$. El presupuesto del sector público ha sido superavitario de manera casi ininterrumpida. Entre 1987 y 2004 el superávit global fue en promedio de $1 \%$ del $\mathrm{PIB}^{3}$. Excepcionalmente se registró déficit de desaceleración del crecimiento y fuerte caída del precio del cobre en los años 1999-2003. Medido en condiciones de tendencia, estos últimos años también exhiben un superávit. Concordante con lo anterior, el riesgo país se ubica en los lugares más bajos entre las economías emergentes y en los rankings de competitividad internacional Chile se sitúa entre los mejor evaluados del mundo en relación con la calidad de su política fiscal.

Lo interesante es que esto no fue siempre así sino, muy por el contrario, durante décadas el país mostraba permanentemente déficit presupuestarios y la deuda pública crecía de manera sostenida. Entre 1950 y 1986

\footnotetext{
${ }^{2}$ La deuda neta de los activos financieros tuvo una reducción aun más marcada. Bajó de 30\% del PIB a -0,3\% en 1998 y a mediados de 2004 alcanzaba a 6\%. Ver "Estadísticas de Deuda Pública" en www.dipres.cl

${ }^{3}$ Éste es el saldo del presupuesto del gobierno central, que incluye todas las entidades públicas con la sola excepción de las empresas y los municipios. El saldo está medido según contabilidad de caja. Pueden verse las "Estadísticas de las Finanzas Públicas" en www.dipres.cl
} 
el déficit promedio fue de 1,9\% del $\mathrm{PIB}^{4}$. La excepción fueron sólo cinco años con superávit.

La fortaleza fiscal de estos últimos dieciocho años ha sido un factor determinante de la reducción en la inflación y del alto crecimiento económico. La política fiscal ha dejado de ser una causa de los desequilibrios macroeconómicos y, por el contrario, ha contribuido, con el resto de la política macroeconómica, a reducir la inflación. Asimismo ello ha permitido hacer una política contracíclica que ha logrado una mayor estabilidad en el crecimiento y el empleo frente a los shocks externos. Gracias a la reducción de la deuda pública y a la situación fiscal, el país pudo enfrentar en condiciones más cómodas los negativos efectos de la crisis asiática de fines de los 90 y compensar en parte sus efectos.

Al mismo tiempo esta política fiscal ha permitido abordar la política social y la de inversión pública con objetivos de mediano plazo y sin sufrir las interrupciones típicas de las situaciones de fragilidad fiscal. El gasto social no sólo no se redujo sino que ha seguido creciendo de manera ininterrumpida ${ }^{5}$.

Resulta por tanto interesante identificar los factores que están detrás de este cambio estructural. Es lo que se examina en este documento. No se pretende realizar un recuento histórico detallado sino más bien indagar cuáles han sido estos factores claves para el cambio estructural. El análisis se hace a partir de la experiencia personal a cargo del presupuesto nacional desde el retorno a la democracia en 1990 hasta fines de 1996 y como observador activo desde otros cargos relacionados con los recursos públicos durante el resto del período.

El análisis y reflexión sobre los factores clave en esta transformación deberían contribuir a cuidar y a preservar los factores que están detrás de esta positiva situación. Asimismo pueden aportar a los estudios de política fiscal que desde la perspectiva comparativa entre países tratan de identificar las razones que explican la gran diferencia en los resultados de la política fiscal que se observan en distintos contextos ${ }^{6}$.

\footnotetext{
${ }^{4}$ Se refiere al déficit del fisco o del Tesoro Público, que es la información disponible para todo el período. Pueden verse los datos en Banco Central de Chile: “Indicadores Económicos y Sociales, 1960-2000”; Ffrench-Davis, Ricardo: "Políticas Económicas 1952-70”; Jofré G., José, Rolf Lüders y Gert Wagner: "Economía Chilena 1810-1995, Cuentas Fiscales” (2000).

${ }^{5}$ Puede verse un recuento de la política social y su relación con la política social en Arellano: "Políticas Sociales para el Crecimiento con Equidad. Chile 19902002” (2004).

${ }^{6}$ Véase una revisión de la literatura sobre el tema en Persson, T. y G. Tabellini: "Political Economics and Public Finance" (1999).
} 
Por último, se examinan algunos desafíos futuros de la política fiscal en Chile que revisten interés para el país y posiblemente en otros contextos.

\section{Atribuciones del ejecutivo y del legislativo en materia fiscal: El marco constitucional y legal}

Un factor determinante del resultado fiscal dice relación con la forma en que se distribuyen las atribuciones entre los distintos actores y con las normas que regulan la discusión, aprobación y ejecución del presupuesto de ingresos y gastos públicos, las facultades de endeudamiento y la legislación económica que altera los ingresos y gastos públicos.

En Chile en las décadas de fuertes déficit y desequilibrios fiscales era común que los Presidentes de la República culparan de ello al hecho de que no contaban con la autoridad para controlar los gastos y administrar el presupuesto público conforme a lo que estimaban conveniente para el manejo económico del país.

La Constitución de 1925 había establecido un régimen presidencial. En 1943, durante el gobierno de Juan Antonio Ríos, se reforzó ese carácter aprobando una reforma constitucional para entregar al ejecutivo la iniciativa en los gastos públicos. Sin embargo en la práctica ello resultaba insuficiente a juicio del ejecutivo. De hecho en todos los gobiernos siguientes los Presidentes Carlos Ibáñez del Campo, Jorge Alessandri y Eduardo Frei Montalva, elegidos con el respaldo de distintos sectores políticos, proponen reformas constitucionales que modifiquen aspectos del orden económico presupuestario fortaleciendo la autoridad presidencial.

Alessandri en julio de 1964, en el proyecto de reforma constitucional, señalaba:

La importancia que paulatinamente han ido cobrando los problemas económico-sociales y la presión consiguiente ejercida por el Congreso en estas materias puso de manifiesto la necesidad de introducir en la Constitución de 1925 modificaciones encaminadas a la defensa de la estabilidad fiscal del país. Para esto se hacía necesario que sólo el Presidente de la República pudiera tener iniciativa en proyectos relacionados con las remuneraciones de los servidores del sector público. Ésta fue la finalidad de la reforma de la Constitución hecha en 1943 y durante la Presidencia de don Juan Antonio Ríos. Indiscutiblemente, el espíritu de ella fue abarcar también los problemas previsionales y así lo estimó el Congreso antes de que yo asumiera la Primera Magistratura. 
Lo que ha ocurrido después de la modificación de 1943 ha puesto en evidencia que en realidad se necesita ir a cambios mucho más radicales que corrijan el mal en su origen [...]. Aquellas prácticas inconvenientes que antes ejercitó el Congreso en la Ley de Presupuesto, se hacen sentir hoy día en todos los proyectos que el Ejecutivo somete a su consideración, especialmente en los de orden social, previsional, financiero, tributario y otros, aparte de que muchas veces los parlamentarios toman directamente la iniciativa de proyectos de ley sobre estas materias que producen efectos aún peores. Cada proyecto es objeto de cientos de indicaciones que desnaturalizan su finalidad, que destruyen otras legislaciones vigentes y que involucran toda clase de materias absolutamente ajenas al proyecto mismo.

Las consecuencias de todas estas iniciativas y de los errores que puedan significar recaen sobre el Presidente de la República, a quien corresponde la administración financiera y económica de la Nación. Si éste tiene la responsabilidad exclusiva de su manejo, lo lógico es que los parlamentarios no tengan derecho alguno de iniciativa en esta materia y que ella pertenezca exclusivamente al Jefe del Estado. Es decir, que tratándose de todos estos problemas, prevalezca el mismo criterio que informa la Constitución de 1925 en lo relativo a la Ley de Presupuestos de la Nación. Sólo así se evitarán las anarquías, injusticias y privilegios en la política de remuneraciones de los asalariados, pertenezcan al sector público o privado, y se lograrán el establecimiento y conservación de un régimen previsional sin favoritismos, la ordenación tributaria y la existencia de una política de inversiones de acuerdo con un plan de desarrollo armónico de la economía nacional.

[...]

Se quiere evitar así que se acentúe la tendencia de volver a la mala práctica de que el Congreso destine a través de la Ley de Presupuestos fondos para obras determinadas, que ha sido en el pasado una de las grandes causas de la imposibilidad de realizar planes de obras públicas debidamente estudiados y cuya realización resulte lo más económica y rápida posible $[\ldots]^{7}$.

${ }^{7}$ En la reforma se propone “[...] que corresponderá al Presidente de la República la iniciativa exclusiva para imponer contribuciones de cualquier clase o naturaleza, suprimir, reducir, establecer exenciones o modificar en cualquier forma las existentes, señalar en caso necesario su repartimiento entre las provincias o comunas y determinar su forma, proporcionalidad o progresión; para contratar empréstitos o celebrar cualquier otra clase de operaciones que puedan comprometer el crédito o la responsabilidad financiera del Estado, de las entidades semifiscales, autónomas de las Empresas del 
Alessandri no tuvo éxito en aprobar su proyecto de reforma a la Constitución, lo que llevó a Frei Montalva, a poco de iniciado su gobierno, a plantear en noviembre de 1964:

Es urgente reservar al Poder Ejecutivo la iniciativa de todas las leyes que impliquen gastos o que interfieran con la planificación necesaria en materia económico social.

Esta disposición que también se está haciendo universal tiene su fundamento en la realidad económica de nuestro tiempo. Es indudable que la enorme complicación de la economía moderna y la necesidad de planificar las inversiones y de señalar metas y prioridades, exige planes no sólo a corto plazo, sino de desarrollo a largo plazo y que requieren unidad de criterio tanto en las inversiones como en los gastos.

Para la eficacia de esos planes, es indispensable asegurar que las metas, objetivos y prioridades pre-establecidas no sean desvirtuadas por iniciativas contradictorias. Aprobada la orientación de la política económica social, corresponde al Gobierno la responsabilidad de su ejecución, lo que exige reservar a éste la iniciativa exclusiva en toda legislación que implique gastos u otras medidas que puedan interferir con el cumplimiento de los planes o programas. Es lo que persigue el proyecto que os propongo al ampliar, en el artículo 45, las materias de ley cuya iniciativa está reservada exclusivamente al Presidente de la República.

Casi seis años pasaron sin que se lograra aprobar esta reforma hasta que finalmente en 1970, al terminar su gobierno, el Presidente Frei Montalva promulga la reforma constitucional señalando:

La autoridad del Ejecutivo debe ser reafirmada en lo que concierne a la planificación del desarrollo y el control del proceso económico y, para este efecto, es necesario extender los pro-

Estado o de las Municipalidades y para condonar, reducir o modificar obligaciones, intereses u otras cargas financieras de cualquier naturaleza, establecidas en favor del Fisco o de cualquiera de los organismos o entidades referidos; para crear nuevos servicios públicos o empleos rentados, sean fiscales, semifiscales, autónomos, de las Empresas del Estado o Municipales, para conceder pensiones de gracia, y en general, de toda ley que signifique gastos al Erario. Le corresponderá, también, la iniciativa exclusiva de las leyes sobre previsión social o que incidan en ella, tanto del sector público como privado, y de aquellas que concedan o aumenten los sueldos, salarios, gratificaciones, o emolumentos, remuneraciones o préstamos de cualquier género del personal en servicio o jubilado del sector privado. [...] El Congreso Nacional sólo podrá aceptar, disminuir o rechazar los servicios, empleos, emolumentos, préstamos, beneficios, gastos, aumentos y demás iniciativas que se proponga, referidas en los dos incisos anteriores”. 
yectos de iniciativa exclusiva del Presidente de la República, a todas las materias que incidan en los gastos fiscales y en el régimen de remuneraciones y de previsión del sector privado. La idea tiene ya un lugar en la Constitución vigente, donde la llevó una reforma que patrocinó el Presidente Ríos [...]. Es imperioso porque la eficacia de la gestión económica del Estado, a la que están ligados todos los sectores de la Nación, hace inevitable radicar esta responsabilidad en el Poder Ejecutivo, el que, por su estructura y la asistencia técnica de que dispone, está en situación de actuar con la coherencia y la continuidad que el Congreso Nacional no puede dar y que son esenciales en todos los países, pero especialmente en tos que están en desarrollo como el nuestro.

El texto aprobado por el Congreso Nacional fue el siguiente (Ley № 17.284 de 23 de enero de 1970):

Corresponderá exclusivamente al Presidente de la República la iniciativa para proponer suplementos a partidas o ítem de la Ley General de Presupuestos para alterar la división política o administrativa del país; para suprimir, reducir o condonar impuestos o contribuciones de cualquier clase, sus intereses o sanciones, postergar o consolidar su pago y establecer exenciones tributarias totales o parciales; para crear nuevos servicios públicos o empleos rentados; para modificar las remuneraciones y demás beneficios pecuniarios del personal de los servicios de la administración del Estado, tanto central como descentralizada; para fijar los sueldos o salarios mínimos de los trabajadores del sector privado, aumentar obligatoriamente sus remuneraciones y demás beneficios económicos o alterar las bases que sirven para determinarlas; para establecer o modificar los regímenes previsionales o de seguridad social; para conceder o aumentar, por gracia, pensiones u otros beneficios pecuniarios y para condonar las sumas percibidas por concepto de remuneraciones u otros beneficios económicos, pensiones de jubilación, retiro o montepío o pensiones de gracia. No se aplicará esta disposición al Congreso nacional y a los servicios que de él dependan.

El gobierno militar que tomó el poder en medio de una seria crisis fiscal introdujo una serie de cambios para centralizar todo el poder en las autoridades del Ministerio de Hacienda y controlar ingresos y gastos públicos. Esos cambios se resumen en una nueva normativa para la administración financiera del Estado (DL 1263) que rige desde $1975^{8}$. Estas normas

\footnotetext{
${ }^{8}$ Reemplaza al DFL 47 que regía desde 1959.
} 
integraron todos los ingresos y gastos de la totalidad de los servicios públicos en el presupuesto de la nación y eliminaron prácticamente todas las afectaciones de impuestos.

En 1980 la nueva Constitución política confirmó y fortaleció la tendencia de las reformas constitucionales que sobre esta materia se habían aprobado en 1943 y 1970. El Presidente de la República concentra las atribuciones para la administración financiera del Estado.

En síntesis, las reformas legales y constitucionales fueron fortaleciendo la autoridad del ejecutivo en materia fiscal hasta llegar al marco legal actual definido en la Constitución de 1980 y en la Ley de Administración Financiera de 1975 con sus posteriores reformas que han reafirmado y ampliado la autoridad presidencial en temas fiscales.

El marco que regula actualmente la política fiscal concentra toda la autoridad en el poder ejecutivo. Las normas constitucionales establecen que las leyes de carácter tributario así como todas las que signifiquen gastos para el fisco, entre las cuales se incluyen las de carácter previsional, son de iniciativa exclusiva del Presidente de la República.

El presupuesto de la nación presentado por el ejecutivo tiene 60 días para su aprobación en el Congreso Nacional, antes del 30 de noviembre de cada año; la estimación de los ingresos es de responsabilidad exclusiva del ejecutivo y los gastos propuestos en el proyecto de presupuesto sólo pueden ser reducidos por el Congreso. Este último no puede presentar iniciativas que reasignen recursos en el proyecto de presupuesto si no se cuenta con el acuerdo del ejecutivo. Si el legislativo no despacha el proyecto de presupuestos en el plazo constitucional, rige el proyecto enviado por el ejecutivo.

Al mismo tiempo las normas de administración financiera establecen una fuerte preeminencia del Ministerio de Hacienda y de la Dirección de Presupuestos en la elaboración, discusión y ejecución del presupuesto. En cuanto al endeudamiento, éste debe ser autorizado por Hacienda en el caso de todas las entidades públicas, incluyendo las empresas, y está prohibido en el caso de los municipios a menos que una ley expresamente lo autorice.

El ejecutivo tiene en la tradición chilena la responsabilidad política por la gestión económica y la administración del Estado, el marco constitucional y legal vigente le otorga las prerrogativas de iniciativa legal y administrativas para hacer efectiva esa responsabilidad.

Esta normativa se ha traducido en una tradición bastante fuerte de disciplina fiscal por la cual los distintos ministerios se sujetan a la autoridad que en los hechos los Presidentes delegan en el Ministerio de Hacienda para asegurarse la buena marcha de la política fiscal. 
Este esquema que concentra la autoridad permite proponerse objetivos de política fiscal y no dejar el resultado fiscal librado a una serie de decisiones generalmente independientes y no necesariamente consistentes de distintos actores, como ocurría en el pasado.

La política fiscal es la más política de las políticas económicas. Involucra la capacidad de disciplinarse ante necesidades múltiples y numerosos beneficiarios y grupos de interés cuando se cuenta con recursos limitados. La política fiscal es tal vez el mejor exponente de la capacidad de gobernabilidad de un sistema económico social. Sólo con muy buenas instituciones y reglas del juego apropiadas la política fiscal se convierte en un instrumento de política macroeconómica. De lo contrario no es posible contar con la política fiscal como instrumento macro.

A nuestro juicio este cambio constitucional y legal que se fue gestando a través de sucesivos gobiernos y que se manifiesta con entera claridad en las actuales reglas del juego son el principal factor que explica el éxito en materia fiscal que se exhibe en los últimos 18 años.

La evidencia comparada entre países llega a conclusiones similares a la que se aprecia de nuestra historia: normas que favorecen la centralización de las decisiones y un sistema altamente jerarquizado de ellas logran un mejor resultado fiscal ${ }^{9}$.

\section{Unidad e integralidad del presupuesto}

Otro cambio, producto de las normas de administración financiera, establece que todos los ingresos y gastos y todas las entidades, con la sola excepción de las empresas públicas y de los municipios, son parte del presupuesto de la nación que aprueba el Congreso. Era común que algunos ingresos propios y/o endeudamientos así como los gastos con cargo a esos

\footnotetext{
9 “Comparaciones entre países sugieren que [...] la centralización de la autoridad presupuestaria en el primer ministro o en el ministro de hacienda [...] restricciones en la posibilidad de alterar los gastos [...] parecen conseguir una mayor disciplina fiscal" (Persson y G. Tabellini: "Political Economics and Public Finance”, 1999, p. 62). Un estudio reciente para los países de la OECD (OECD, Economic Outlook N ${ }^{\circ} 74,2003$ ), capítulo IV: "Fiscal stance over the cycle: the role of debt, institutions, and budget constraints”, concluye que el carácter de la política fiscal está influido por la institucionalidad que la regula y que ella tiende a ser pro cíclica en las situaciones de mayor fragmentación en las decisiones. Es notable que a pesar de la importancia de las reglas que regulan la preparación y aprobación de presupuestos, sólo en los últimos 15 años se ha reconocido su importancia en los estudios sobre el tema. Hasta fines de los años 80 ni siquiera entre los países de la Unión Europea existían estudios comparativos de sus prácticas presupuestarias.
} 
ingresos no formaran parte del presupuesto. Ello creaba distintas instancias de negociación y decisiones respecto del monto global de gastos e ingresos que dificultaban conseguir el resultado presupuestario deseado.

Esta fragmentación presupuestaria que caracterizaba nuestro sistema hasta la dictación de la Ley de Administración Financiera del Estado de $1975^{10}$ y que aún es común en muchos países lleva a que se decidan con bastante autonomía partes del presupuesto en distintos momentos e instancias, dificultando la discusión y consecución de un objetivo fiscal global.

La contraparte de la integralidad es una mayor flexibilidad en la ejecución otorgada a quienes administran los recursos, permitiendo reasignaciones de fondos de acuerdo a lo que recomiende una mejor administración. En la ley de presupuestos se aprueban los ingresos y los gastos de manera bastante agregada; por ejemplo, hay una sola línea para gastos en personal, otra para bienes y servicios y algunas líneas para transferencias cuando se quiere identificar programas.

\section{Fortalecimiento del sistema tributario}

Un factor esencial para una sana política fiscal es un sistema tributario capaz de recaudar los recursos necesarios para financiar los gastos presupuestados. Un sistema tributario que descanse en leyes que definan bases tributarias estables y que permita una administración eficaz parece indispensable para una política fiscal sólida.

En este aspecto el sistema tributario chileno ha ido progresando a lo largo de varias décadas hasta llegar a la situación actual. Una de las fuentes de fragilidad era la inflación que erosionaba la recaudación. Ello empezó a evitarse con la indexación del sistema tributario en los años 60 hasta llegar a la situación actualmente vigente desde 1975, en que el sistema está íntegramente indexado a unidad de cuenta que se corrige día a día según la inflación medida por el IPC del mes anterior ${ }^{11}$. Esto hace que la recaudación tributaria esté totalmente protegida frente a la inflación.

Por otra parte, la indexación permite que la legislación tributaria sea de carácter permanente y no tenga que revisarse en cada ejercicio presupuestario. De hecho en las leyes de presupuesto no se incluye ninguna

\footnotetext{
${ }^{10}$ Hasta 1975, el presupuesto era fiscal y los presupuestos de los organismos autónomos y descentralizados generalmente se sancionaban por decreto durante el ejercicio, dificultando el control global del gasto público.

${ }^{11}$ Para el sistema tributario generalmente se usan la UTM o UTA, unidades tributarias mensuales o anuales, que siguen el comportamiento del índice de precios. La unidad de cuenta de uso más difundida es la UF introducida en los años 60.
} 
norma de carácter tributario sino únicamente las estimaciones de la recaudación que producirá la legislación permanente. Ello hace posible que la legislación tributaria se discuta con una perspectiva de mediano y largo plazo y no en virtud de las necesidades financieras del año.

En la administración tributaria se ha producido un sostenido avance en los últimos veinte años que ha reducido significativamente la evasión. Se elevaron las capacidades del Servicio de Impuestos Internos, se le otorgaron mayores facultades de fiscalización y se eliminaron vacíos legales que facilitaban la evasión y/o elusión tributaria ${ }^{12}$. La calidad de la administración tributaria por su probidad y seriedad y por el creciente uso de las nuevas tecnologías de información la ha situado entre las más modernas del mundo.

En cuanto a los efectos del sistema tributario sobre la asignación de recursos, si bien ése no es el objeto de este estudio, su neutralidad procura disminuir al máximo los desincentivos y distorsiones en el aparato productivo.

Durante los últimos diez años se ha producido un cambio importante en la composición de los ingresos tributarios para acomodar las sucesivas rebajas arancelarias unilaterales o producto de acuerdos bilaterales de libre comercio que han reducido el arancel promedio al $2 \%$ y que han disminuido desde $10 \%$ hasta $1,5 \%$ la significación de los impuestos al comercio exterior dentro de la recaudación tributaria.

Otro criterio valioso para un buen resultado fiscal desde el punto de vista macroeconómico ha sido la prohibición de afectar los impuestos por ley a un determinado gasto ${ }^{13}$. La afectación de los ingresos produce rigideces e impide una asignación de los recursos conforme a las cambiantes prioridades. La no afectación permite que se privilegien los objetivos macroeconómicos de interés general y que se asignen los recursos conforme a las prioridades de cada momento.

En el momento de afectar un determinado nuevo tributo a un objetivo específico ello puede parecer muy razonable, sin embargo lo común es que con ese criterio se va acumulando una gran cantidad de afectaciones que limitan enormemente la administración de los recursos y crean toda suerte de rigideces.

\footnotetext{
12 Una revisión de las principales iniciativas para combatir la evasión y sus resultados en el período 1990-2005 puede verse en http://www.sii.cl/ aprenda_sobre_impuestos/estudios/adminis_tributaria.htm

${ }^{13}$ La única excepción son los ingresos provenientes del cobre que financian a las fuerzas armadas. Existe un creciente consenso respecto de la eliminación de esta excepción al criterio que prohíbe la afectación.
} 
Es cierto que los impuestos se crean para atender alguna necesidad y para financiar determinados programas y por tanto en la discusión pública y legislativa hay que ofrecer las justificaciones en términos de los programas específicos que un determinado impuesto financiará. Sin embargo eso es muy distinto a dejar obligado el destino del impuesto, cuya base y cuya recaudación cambiarán a través del tiempo.

En una visión menos benévola, los impuestos con destinaciones específicas pueden surgir de intereses de grupos que logran imponer sus intereses. La no afectación impide que ventajas producto de victorias legislativas pasajeras puedan traducirse en beneficios e inequidades permanentes difíciles de corregir.

Resulta muy valiosa por tanto la actual norma constitucional que impide la afectación de impuestos.

\section{Capacidad de control de endeudamiento de las entidades autónomas}

La contrapartida de los déficit es el endeudamiento. De allí la importancia para la política fiscal de contar con un control centralizado del endeudamiento de las entidades públicas. De acuerdo al actual marco normativo, aquellas entidades que forman parte del gobierno central necesitan autorización de Hacienda para iniciar conversaciones de endeudamiento y toda la relación con los organismos multilaterales de crédito (Banco Mundial, BID) está centralizada en la Dirección de Presupuestos. De esta forma se puede ordenar la política de crédito público conforme a un interés común.

Las empresas públicas que en razón de su naturaleza no aprueban presupuesto por ley sino por decreto de Hacienda requieren de autorización expresa de ese ministerio para contratar créditos.

Las municipalidades, que gozan de autonomía presupuestaria, no pueden endeudarse a menos que una ley las autorice. El ejecutivo no ha propuesto ninguna ley para autorizar el endeudamiento municipal en los últimos quince años.

La ley de gobiernos regionales de 1992 estableció expresamente que los gobiernos regionales no pueden endeudarse. El objetivo explícito de esa reforma fue favorecer la descentralización en la asignación de los recursos de inversión pero sin arriesgar la capacidad de control del endeudamiento público y el objetivo de política fiscal establecido por el gobierno central. Por ello, junto con ampliar las atribuciones de los gobiernos regionales y otorgarles un presupuesto propio, se tuvo especial cuidado que esto no significara arriesgar la capacidad de Hacienda para controlar el nivel global de gastos. El nuevo rol de los gobiernos regionales ha significado una 
creciente capacidad de asignación de los recursos a distintos proyectos de inversión, pero conforme a un marco determinado centralmente. Esto se ha traducido en un fuerte aumento de la inversión pública definida a nivel de cada región. En 1992 sólo el 18\% de la inversión del gobierno central era asignada a nivel de las regiones; actualmente esa proporción llega al 50\%.

Estas normas que limitan las facultades de endeudamiento son complementadas por una estricta fiscalización por parte del supervisor de las entidades bancarias y financieras que asegura que las instituciones financieras colaboren en el cumplimiento de estas disposiciones.

A medida que se han desarrollado nuevos mecanismos de inversión privada en base a concesiones, el Estado ha asumido garantías para reducir el riesgo y facilitar la inversión de los privados. Estos pasivos contingentes no pueden ser asumidos sin la autorización de Hacienda.

Como una norma de sana transparencia y contabilización de los riesgos, recientemente se ha establecido un registro de pasivos contingentes del sector público que explicita los compromisos del Estado por estos conceptos $^{14}$.

\section{Consenso político en la importancia de la disciplina fiscal. La lección de las crisis macroeconómicas}

En un contexto democrático el marco normativo se sostiene en la medida en que se perciba que ese marco contribuye al interés común en un grado tal que justifique postergar intereses de grupos. Sin ese consenso las normas terminan siendo resistidas y modificadas. Ese consenso ha sido permanente en los últimos quince años, sin perjuicio del reclamo por falta de atribuciones de los legisladores en la discusión del presupuesto.

A lo largo de quince años de democracia se ha ido perfeccionando la práctica de discusión y aprobación del presupuesto y mejorando la cantidad y calidad de la información y su debate ${ }^{15}$. El marco legal se ha mantenido en lo esencial y en su aplicación se han perfeccionado anualmente las normas de las leyes de presupuesto, a la vez que mediante legislación especial se ha actualizado la Ley de Administración Financiera ${ }^{16}$.

\footnotetext{
${ }^{14}$ Véase una estimación de estos pasivos a fines de 2003 en http:// www.dipres.cl/presupuesto/documentos/Informe_Finanzas_Publicas_2004.html

${ }^{15}$ Puede verse el Informe del FMI en el 2003 sobre transparencia fiscal, que destaca el nivel alcanzado y los avances de los últimos años en http://www.dipres.cl/ publicaciones/informe_FMI.html

${ }^{16}$ La Ley $\mathrm{N}^{\circ} 19.908$ de octubre de 2003, por ejemplo, hace extensivas las normas de control de endeudamiento a los swaps. La N 19.896 de septiembre de 2003 establece obligaciones de informar periódicamente.
} 
Las reglas del juego que establecen las atribuciones y facultades de los actores han fortalecido el cuidado del objetivo macroeconómico del presupuesto y de la política fiscal ${ }^{17}$. Pruebas de ello son el funcionamiento del fondo de estabilización del cobre y las reglas de política fiscal que se analizan más abajo.

Detrás de ese consenso político está el reconocimiento de la importancia de la solidez fiscal y el reconocimiento de los altos costos que el país pagó en el pasado en los episodios de desequilibrios fiscales y crisis macroeconómicas. Al mismo tiempo la práctica ha demostrado los frutos benéficos de esta política que produce un "dividendo fiscal”. La reducción de la deuda de gobierno, por ejemplo, permitió afrontar de manera sólida las crisis externas y el menor pago de intereses por esa deuda ha liberado recursos para financiar el gasto social.

Con el retorno a la democracia en 1990 el factor de consenso principal en la coalición gobernante ${ }^{18}$ era evitar los riesgos de un desborde fiscal y desequilibrios macroeconómicos. La crisis política de 1973 y la grave crisis económica de 1982 estuvieron asociadas a desequilibrios macro cuyos altísimos costos estaban muy presentes en la memoria de todos los actores.

Quienes en esos años podían discrepar o dudar de la política fiscal y de un marco legal como el que aquí se describe se sometieron al consenso en pro de evitar los riesgos de la inestabilidad. Con los años la política fue mostrando sus méritos y por tanto el consenso radica en los dividendos de la política fiscal. En particular en su capacidad de sustentar el gasto social en situaciones de dificultades externas, en la reducción de la inflación, en la caída del riego país y en la mayor predictibilidad de la política fiscal.

\section{Mecanismos para una política fiscal sostenible y que contribuya a una acción contracíclica: El Fondo del Cobre y la regla de política fiscal}

\footnotetext{
U A partir de 1987 se creó un Fondo del Cobre y en 2001 una regla de política fiscal. Ambos mecanismos han buscado definir la política fiscal de acuerdo a criterios que le den sustentabilidad de largo plazo. Es interesante examinar su impacto y efectos en la política fiscal.

${ }^{17}$ Puede verse la positiva evaluación de una misión de la OECD solicitada por el gobierno para examinar las prácticas presupuestarias. OECD (2004).

${ }^{18}$ La coalición gobernante ha sido la Concertación de Partidos por la Democracia, una coalición de centro izquierda.
} 


\section{a) El Fondo del Cobre}

Ha sido tradicional en Chile el fuerte impacto de los ciclos de precios del cobre sobre los ingresos públicos. El cobre representa actualmente menos del 5\% de los ingresos tributarios pero en algunos períodos superó el 17\%. Sus ciclos tradicionalmente afectaban de manera decisiva la situación de las finanzas públicas ${ }^{19}$. Para contrarrestar el efecto de esas variaciones se creó el fondo de estabilización de ingresos del cobre, que ha estado en operación desde $1987^{20}$.

El propósito básico es ahorrar recursos cuando el precio del año supera el precio de largo plazo, a fin de recurrir a esos ahorros cuando esté por debajo. En el Anexo se describe la operación del Fondo del Cobre y su comportamiento durante los últimos quince años. Aquí interesa examinar su impacto en la efectividad de la política fiscal.

Un efecto importante del Fondo del Cobre es que ha ayudado a administrar la bonanza y ha permitido prepararse para las dificultades. Antes que existiera este mecanismo era común que en los años de bonanza el gasto público se expandiera conforme al aumento de ingresos, dificultando su reducción en los momentos de bajos precios. El Fondo del Cobre evita expandir los gastos más allá de lo sustentable en el mediano plazo y proporciona financiamiento para darles continuidad cuando los precios bajan.

En los años de bonanza los recursos acumulados en el Fondo se usaron para reducir la deuda externa.

La capacidad de la política fiscal para hacer política contracíclica se define en los momentos de expansión y bonanza, en los momentos altos del ciclo. Si en la bonanza se ha reducido la deuda, los momentos de estrechez se enfrentarán con menores gastos del servicio de deuda y los mercados verán con mayor confianza y sin temores de su sustentación de largo plazo las necesidades de endeudamiento que puedan surgir en esas circunstancias $^{21}$. De esta forma Chile ha estado entre los pocos países en el mundo que pueden darse el lujo de contar con la posibilidad de usar la política fiscal como un instrumento de política macroeconómica contracíclica ate-

\footnotetext{
${ }^{19}$ Sobre la importancia del cobre puede verse Meller, Patricio: Dilemas y Debates en Torno al Cobre (2002).

${ }^{20}$ En 1981 a través del DL $N^{\circ} 3.653$ se había establecido un mecanismo de precio de referencia del cobre para destinar ingresos por sobre un nivel de referencia al pago de deudas.

${ }^{21}$ En OECD, Economics Department: Economic Newsletter, junio 2004, se concluye que para varios países de la OECD la política fiscal se hizo más procíclica en las décadas del 80 y del 90 debido a que la acumulación de deuda pública no hizo posible aplicar políticas expansivas en el momento negativo del ciclo.
} 
nuando la magnitud del ciclo. En las crisis el margen de maniobra es muy limitado y por tanto la capacidad de hacer política contracíclica y de estabilización que no se genera en la bonanza difícilmente estará disponible en circunstancias de crisis.

\section{b) La regla de superávit estructural}

Más recientemente a partir de 2001 se amplió el mecanismo de estabilización por fluctuaciones en el precio del cobre hacia uno que agrega las fluctuaciones de ingresos producto de las variaciones en el PIB con respecto a su tendencia de largo plazo. Se ha establecido un cálculo de los ingresos en base al PIB de tendencia de forma tal de definir los gastos en base a la capacidad de recaudación tributaria de tendencia de mediano plazo y no de la situación coyuntural de cada año. Así, se ha fijado un objetivo de política fiscal en base al saldo estructural del presupuesto.

No sólo se ha ampliado la base de ingresos que se estabiliza conforme a las tendencias de largo plazo, se ha dado un paso adicional al introducir una regla de política fiscal que establece una meta de $1 \%$ de superávit estructural. Véase una descripción de la regla de superávit estructural en Marcel et al. (2001) y en la Exposición de Hacienda 2001.

La regla de política fiscal que se introdujo en base al 1\% del PIB de superávit estructural amplió la base de ingresos, que se estabiliza, y además fijó un marco a la política contracíclica.

En los casos en que es posible hacer política fiscal contracíclica siempre será discutible el grado en que es apropiado hacerlo y con toda seguridad en medio de las dificultades de la crisis habrá una tendencia natural a presionar por el máximo uso de la acción contracíclica. La regla de política fiscal del $1 \%$ de superávit deja de lado este fine tuning pero gana en credibilidad y pone un marco claro ex ante de lo que resulta prudente hacer en materia fiscal contracíclica.

La regla ha permitido en los últimos años una acción contracíclica bastante significativa. En 2001 y 2002 se realizó un gasto fiscal entre 1,4 y 1,7\% del PIB en base a la regla fiscal. El Fondo del Cobre permitió que en cada uno de esos dos años se financiara el equivalente a 1\% del PIB de gastos con cargo a esos recursos. (El Fondo y sus criterios de ahorro y gasto está incorporado en la regla de política fiscal.)

Estos mecanismos de estabilización cumplen una importante función política, fijan prioridades y tienen también un rol pedagógico. Se hace explícito que hay un objetivo macro que el presupuesto debe cumplir. Esta- 
blecen un compromiso político. Sirven para marcar el compromiso con un objetivo fiscal por parte de las autoridades y reducen la necesidad de negociaciones alrededor del nivel del saldo presupuestario deseable en cada coyuntura. Asimismo refuerzan la disciplina fiscal, ya que hacen más costoso el desequilibrio, porque ello significaría romper un compromiso más preciso de comportamiento fiscal.

Estos mecanismos ayudan a repartir responsabilidades políticas y hacen más fácil asumir el costo de no poder atender todas las demandas que existen en una coyuntura de bajos ingresos, así como a limitar el interés por usar todos los ingresos en la bonanza. La regla ayuda a poner un límite, ya que siempre puede argumentarse que las circunstancias especiales de cada coyuntura justificarían una política más expansiva, lo que es más fácil de plantear cuando la política es discrecional.

La automaticidad de la regla permite superar las dificultades para construir acuerdos en situaciones de cambios en las mayorías legislativas y en coyunturas de mayor competencia política. Por la misma razón estos mecanismos facilitan la implementación de la política fiscal y la rapidez en comparación con lo que ocurriría si las medidas fueran de tipo discrecional. Una regla así cuando ha ganado credibilidad puede ser una señal de sustentabilidad para los mercados financieros y producir beneficios en términos de acceso y costos del financiamiento. La política discrecional en cambio supone mayor capacidad de la autoridad económica para imponer y hacer creíble a los mercados que ésa es la política ideal desde el punto de vista macro y por tanto justificable de acuerdo con las características particulares de cada ciclo.

Sabemos lo importante, indispensable, que es la credibilidad para una buena política económica. Esta regla contribuye a elevar la credibilidad de la política fiscal y de la política macro en general haciéndola más eficaz y reduciendo los costos de ajuste.

Estos mecanismos de estabilización han contribuido a crear un cierto sentido común sobre lo que es aceptable y deseable en materia de política fiscal.

Estos mecanismos no sólo dan una sustentabilidad de mediano plazo a la política fiscal con todos los beneficios que se han destacado, también amplían el horizonte de planeación de las entidades públicas. Es posible pensar y programar iniciativas de mediano plazo sin tener la extrema incertidumbre de su viabilidad presupuestaria, tan común en décadas pasadas y en países donde no se ha logrado la sustentabilidad fiscal.

Es interesante anotar que ni el Fondo del Cobre ni la regla de superávit estructural están definidos en una ley. Estos mecanismos son buenas 
políticas que el ejecutivo ha introducido y se han legitimado en la práctica y han ido mejorando su aplicación concreta a través del tiempo. Un perfeccionamiento para ganar credibilidad y fortalecer estas reglas ha sido la iniciativa que desde 2002 establece que los parámetros clave para estimar el precio del cobre de largo plazo y el crecimiento tendencial del PIB, que se utilizan para definir el superávit estructural, son determinados por un panel de expertos independientes del gobierno. Ello le aporta credibilidad y despeja las dudas de discrecionalidad a que pueden estar expuestos este tipo de mecanismos.

\section{La disciplina de los mercados y la autonomía de la política monetaria}

Un factor complementario que contribuye a la disciplina fiscal está dado por el rol de los mercados financieros y de la política monetaria. La autonomía del Banco Central, vigente en Chile desde 1989, lleva a que un grupo de personas independientes de quienes definen la política fiscal está evaluando el efecto macro de la política fiscal y si la consideran más expansiva de lo deseable desde el punto de vista de la estabilidad de precios, pueden elevar las tasas de interés, generando un costo para esa política fiscal. Un rol similar juegan los mercados financieros que están evaluando la sustentación de la política fiscal, lo que influirá sobre el riesgo país y por tanto sobre el costo de fondos.

Éstos son elementos nuevos y que refuerzan la disciplina fiscal, pero no han sido en la experiencia chilena los factores determinantes, como algunos podrían pensar. Estos factores han reforzado y consolidado lo que la política fiscal ha venido haciendo en base a los factores que se anotaron más arriba. La autonomía de la política monetaria y los mercados financieros no pueden transformar una mala política fiscal en una buena política fiscal, pero una vez que se logra el cambio lo refuerzan y lo consolidan ${ }^{22}$.

\section{Conclusión}

En el análisis económico y las recomendaciones de políticas se viene dando un reconocimiento cada vez mayor al rol de las instituciones. La transformación de los resultados macroeconómicos en Chile y en particular

\footnotetext{
${ }^{22}$ En cierta medida hacen lo mismo con la mala política fiscal. Los mercados financieros la castigan elevando el costo financiero y haciendo más deficitarias las cuentas fiscales.
} 
el dramático cambio en la política fiscal es un claro ejemplo de la importancia de los cambios institucionales y del efecto muy positivo que pueden tener mejores instituciones.

El conjunto de cambios institucionales que se han descrito son los responsables de que Chile pasara de déficit crónicos a superávit estructurales. Ello le ha permitido al país cosechar el dividendo fiscal. Éste se ha traducido en mayor estabilidad y crecimiento más alto. Se ha traducido también en una mejor calidad de los servicios que financia el Estado. En paralelo a los buenos resultados macroeconómicos, ha sido posible ir logrando una política fiscal más redistributiva y una modernización del Estado. En estos ámbitos hay muchos desafíos pendientes, pero sin duda la disciplina fiscal permite concentrar los esfuerzos y la energía en mejorar la calidad de los servicios públicos.

\section{ANEXO}

El Fondo de estabilización de precios del cobre en Chile

Este Fondo se estableció en 1987 después de una crisis a principios de esa década. Era una antigua idea que nunca se había implementado formalmente. La justificación para un fondo de estabilización es que el precio del cobre es muy fluctuante y los ingresos fiscales por utilidades de Codelco (la empresa estatal que produce y exporta el cobre) representan cerca del 5\% de los ingresos corrientes del gobierno y una proporción mayoritaria de sus ingresos en moneda extranjera.

El sistema opera básicamente de la siguiente forma:

Se fija un precio de referencia anticipadamente para cada año — esto se hace anualmente teniendo en cuenta lo que se consideran las tendencias de mediano plazo o el precio más permanente-. Durante los 90 se fijaba el precio de referencia mirando, además de la tendencia del precio, el conjunto de la política fiscal. A partir de 2001 y a fin de darle independencia de las autoridades se estableció un comité de expertos que año a año recomienda el precio de tendencia a utilizar para el Fondo.

Véase en el Cuadro $\mathrm{N}^{\circ} 1$ una serie con los precios de referencia y los efectivos. Si el precio en el año se eleva por sobre la referencia hasta en cuatro centavos de dólar, esos fondos son de libre disponibilidad fiscal. Por los siguientes 6 centavos debe ahorrarse el 50\% de los mayores ingresos. Por encima de 10 centavos del precio de referencia, esos recursos se ahorran y se integran completamente al Fondo del Cobre.

Cuando el precio se sitúa por abajo del nivel de referencia, se actúa en forma simétrica. Por los primeros 4 centavos no hay derecho a acceder al 


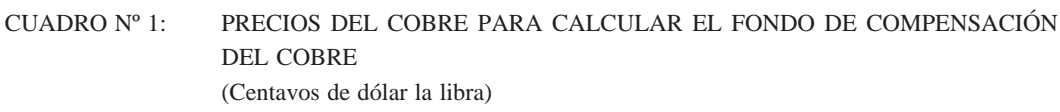

\begin{tabular}{llr}
\hline & Precio de referencia & Precio efectivo \\
& & \\
1987 & $61,5^{*}$ & 81,1 \\
1988 & 71,0 & 117,9 \\
1989 & 75,0 & 129,1 \\
1990 & 79,0 & 120,9 \\
1991 & 82,0 & 106,1 \\
1992 & 93,0 & 103,6 \\
1993 & 96,0 & 86,7 \\
1994 & 96,0 & 104,9 \\
1995 & 96,0 & 133,2 \\
1996 & 96,0 & 103,9 \\
1997 & 96,0 & 103,2 \\
1998 & 96,0 & 75,0 \\
1999 & 92,0 & 71,4 \\
2000 & 92,0 & 82,3 \\
2001 & 92,0 & 71,6 \\
2002 & 90,0 & 70,6 \\
2003 & 88,0 & 80,7 \\
2004 & 88,0 & 130,0 \\
& &
\end{tabular}

Fuente: Dirección de Presupuestos y Banco Central de Chile.

Fondo, por los siguientes 6 centavos se puede girar hasta el 50\% de los menores ingresos desde el Fondo y cuando excede los 10 centavos el fisco puede compensar enteramente los menores ingresos con giros del Fondo.

Los cálculos se hacen trimestralmente tomando en cuenta las ventas efectivas de Codelco y los precios efectivos de exportación.

Los fondos se mantienen en una cuenta del fisco con el Banco Central, a quien se le tiene encomendada la inversión financiera de estos recursos. Véase en el Cuadro $\mathrm{N}^{\circ} 2$ una serie de depósitos y giros del Fondo.

En cuanto al uso de los fondos existe bastante flexibilidad.

El temor al retorno de la democracia y a la temida irresponsabilidad fiscal llevó al gobierno de la época a desembolsar todos los recursos a fines del 89 destinándolos al pago de deuda pública.

En 1990, a raíz de la crisis del golfo y la fuerte alza del precio del petróleo, se usó parte del Fondo de estabilización para crear un fondo estabilizador de precios y gastos en petróleo, pero con la obligación de reintegrar los fondos cuando bajaran los precios internacionales del petróleo. En buena medida así se hizo. 
JOSÉ PABLO ARELLANO

CUADRO N 2: MOVIMIENTO Y SALDO FONDO DE COMPENSACIÓN DEL COBRE

(Miles de US\$)

\begin{tabular}{lrrrr}
\hline & $\begin{array}{c}\text { Ingresos } \\
\text { del año }\end{array}$ & $\begin{array}{c}\text { Usos } \\
\text { del año }\end{array}$ & $\begin{array}{c}\text { Ingr. neto } \\
\text { del año }\end{array}$ & $\begin{array}{c}\text { Saldo } \\
\text { (Incluyendo } \\
\text { devolución petróleo) }\end{array}$ \\
\hline 1987 & 26.361 & 0 & 26.361 & 26.361 \\
1988 & 495.997 & 439.508 & 56.489 & 82.850 \\
1989 & 1.202 .962 & 1.260 .064 & -57.102 & 25.748 \\
1990 & 785.062 & 256.180 & 528.882 & 554.630 \\
1991 & 289.669 & 200.000 & 89.669 & 644.299 \\
1992 & 134.647 & 0 & 134.647 & 778.946 \\
1993 & 9.810 & 38.991 & -29.181 & 749.765 \\
1994 & 46.472 & 101.440 & -54.968 & 701.481 \\
1995 & 664.256 & 0 & 664.256 & 1.365 .737 \\
1996 & 324.421 & 7.323 & 317.098 & 1.682 .835 \\
1997 & 117.640 & 0 & 117.640 & 1.800 .475 \\
1998 & 3.760 & 273.486 & 269.726 & 1.530 .753 \\
1999 & 63.440 & 516.019 & -63.440 & 1.078 .172 \\
2000 & 0 & 404.770 & -404.770 & 673.406 \\
2001 & 250.000 & 302.260 & -52.260 & 621.150 \\
2002 & 138.940 & 483.040 & -344.100 & 277.050 \\
2003 & 0 & 202.450 & -202.450 & 74.602 \\
2004 & & & & 207.823 \\
& & & & \\
\hline
\end{tabular}

Fuente: Dirección de Presupuestos.

En los años siguientes se redujo la deuda pública. No sólo se disminuyó fuertemente la contratación de nuevo endeudamiento externo sino que se prepagó deuda externa. En todo el período nunca se recurrió al endeudamiento interno. Dadas las condiciones de esos créditos, su prepago era una buena inversión financiera. La deuda pública pasó de representar el 47,2\% del PIB en 1990 al 14,2\% en 2000. La deuda externa del sector público se redujo de 12.250 millones de dólares en 1989 a 5.300 millones a fines del 2000.

- Es interesante destacar que este mecanismo de estabilización de precios no está estipulado en ninguna ley permanente.

Naturalmente que año a año se incluye en la ley de presupuestos y en su discusión se informa al Congreso Nacional una estimación del comportamiento del Fondo.

En general se le ha dado una baja visibilidad y se anotan en la ley de presupuesto sólo los recursos que se pueden gastar.

Desde 2002 los precios de referencia los fija un comité de expertos cuyos informes pueden verse en www.dipres.cl 


\section{REFERENCIAS}

Alesina, A., R. Hausmann, R. Hommes y E. Stein (1999): "Budget Institutions and Fiscal Performance in Latin America”. En Journal of Development Economics, 59.

Alesina, A. y R. Perotti (1995): “The Political Economy of Budget Deficits”. IMF staff paper, marzo.

Alesina, A. y R. Perotti (1999): “Budget Deficits and Budget Institutions”. En J. Poterba y J. Hagen (eds.), Fiscal Institutions and Fiscal Performance. The University of Chicago Press.

Arellano, José Pablo (2004): "Políticas Sociales para el Crecimiento con Equidad. Chile 1990-2002”. Santiago: Cieplan, 2005. www.cieplan.cl

Banco Central de Chile: "Indicadores Económicos y Sociales, 1960-2000".

Dirección de Presupuestos Ministerio de Hacienda Chile: "Estadísticas de las Finanzas Públicas”. En www.dipres.cl

Ffrench-Davis, Ricardo (1978): Políticas Económicas 1952-70. Santiago: Ediciones Universidad Católica de Santiago.

Jofré G., José, Rolf Lüders Sch. y Gert Wagner (2000): “Economía Chilena 1810-1995 Cuentas Fiscales”. Documento de Trabajo No 188, Instituto de Economía Pontificia Universidad Católica de Chile.

Marcel, Mario y Marcelo Tokman (2003): "Building a Consensus for Fiscal Reform: The Chilean Case OECD”.

Marcel, M., M. Tokman, R. Valdés y P. Benavides (2001): "Balance Estructural del Gobierno Central. Metodología y Estimaciones para Chile: 1987-2000”. En Estudios de Finanzas Públicas, septiembre. http://www.dipres.cl/ fr_publicaciones.html

Meller, Patricio (2002): Dilemas y Debates en Torno al Cobre. Santiago: Dolmen Ediciones.

Ministerio de Hacienda (2001): "Exposición sobre el Estado de la Hacienda Pública”.

OECD (2003): Economic Outlook, No 74. París.

OECD (2004): Budgeting in Chile 25th Annual Meeting of Senior Budget Officials Spain 9-10 June.

OECD (2004): Economics Department, Economic Newsletter, junio.

Persson, T. y G. Tabellini (1999): "Political Economics and Public Finance”, NBER Working Paper 7097.

Vial, Joaquín (2001): “Institucionalidad y Desempeño Fiscal: Una Mirada a la Experiencia Chilena en los 90”, Santiago, CIEPLAN, www.cieplan.cl 